\title{
Bidens pilosa Ethylene acetate extract can protect against L-NAME-induced hypertension on rats
}

\author{
Danielle Claude Bilanda", Paul Désiré D. Dzeufiet', Léontine Kouakep', Bibi Farouck O. Aboubakar', \\ Léonard Tedong ${ }^{2}$, Pierre Kamtchouing ${ }^{1}$ and Théophile Dimo ${ }^{1}$
}

\begin{abstract}
Background: Essential hypertension is mainly caused by endothelial dysfunction which results from nitric oxide (NO) deficiency. The present study was design to evaluate the protective effect of Bidens pilosa ethylene acetate extract (Bp) on L-NAME induced hypertension and oxidative stress in rats.
\end{abstract}

Methods: Male Wistar rats were used to induce hypertension by the administration of L-NAME (a non-pecific nitric oxide inhibitor) (50 mg/kg/day). The others groups were receiving concomitantly L-NAME plus Bp extract (75 and $150 \mathrm{mg} / \mathrm{kg} /$ day) or losartan ( $25 \mathrm{mg} / \mathrm{kg} /$ day). All the treatments were given orally for 4 weeks. At the end of the treatment, the hemodynamic parameters were recorded using the direct cannulation method. The effects of the extract on lipid profile, kidney and liver functions as well as oxidative stress markers were evaluated by colorimetric method. Results were expressed as the mean \pm SEM. The difference between the groups was compared using one-way analysis of variance (ANOVA) followed by the Duncan's post hoc test.

Results: Animals receiving L-NAME presented high blood pressure, normal heart rate and lipid profile as well as NO depletion, liver and kidney injuries and oxidative stress. The concomitant treatment with L-NAME and Bp or losartan succeeded to prevent the raised of blood pressure and all the other injuries without affecting the heart rate.

Conclusion: These results confirm the antihypertensive effects of Bidens pilosa and highlight its protective properties in L-NAME model of hypertension in rat, probably due to the presence of Quercetin 3,3 '-dimethyl ether 7-0- $\beta$-D-glucopyranoside.

Keywords: Bidens pilosa, L-name, Hypertension, Oxidative stress, Rat

\section{Background}

Essential (or primary) hypertension is mainly caused by endothelial dysfunction which results from nitric oxide (NO) deficiency [1]. In fact, it has been found that vascular endothelium of hypertensive patients produces less nitric oxide. NO released by endothelial cells is an important regulator of vascular function [2]. Therefore, chronic administration of Nw-nitro-L-arginine methyl ester (L-NAME) a non-pecific nitric oxide inhibitor causes arterial hypertension in rats [3]. L-NAME-induced hypertension is then a suitable model to test the

\footnotetext{
* Correspondence: bilandad@yahoo.comm

'Department of Animal Biology and Physiology, Laboratory of Animal Physiology, University of Yaounde I, P.O. Box 812, Yaounde, Cameroon Full list of author information is available at the end of the article
}

vascular protective effects of antihypertensive drugs in the context of NO deficiency [3]. Plant extracts used in the treatment of many diseases contain natural antioxidants that can prevent ROS formation and its damages [4]. Moreover some flavonoid have proved to ameliorate hypertension, oxidative stress and lipid metabolism in L-NAME hypertensive rats [5].

Bidens pilosa which is used in the current study, is a medicinal plant belonging to the family of Asteracae with a widely occurrence in the tropical and hot areas of Africa, including Cameroon. This plant is used in traditional medicine for at least 40 categories of illnesses, including hypertension $[6,7]$. The plant has already been tested for it hypotensive and antihypertensive activities on many models of hypertension such as spontaneously 
hypertensive rats (SHR), salt-loading and fructoseinduced hypertensive rats [8-10] and even human cells [11]. The mechanism of action of the extracts from Bidens pilosa include vasodilatation, calcium blocker, free radicals scavenging insulin-sensibility, lipid profil improving [10-13]. The interest on bioactive compounds from plant extracts has increased in recent years due to their health benefits, particularly protection against a variety of ailments such as cardiovascular diseases [14]. Bidens pilosa is now knowm to contain several chemical and useful compounds, including at least 60 flavonoids [7]. In the present plant extract, we identified two bioactive flavonoids namely Quercetin 3,3 '-dimethyl ether 7-0- $\beta$-Dglucopyranoside and Iso-Okanin 7-O- $\beta$-D-(2 “, 4", 6 "-triacetyl)-glucopyranoside [15]. Quercetin is known to improve vascular function in an endothelium-dependant and -independent manner [16]. Wistar rat is a suitable model of essential hypertension caused by endothelial dysfunction. Therefore, the purpose of this study was to evaluate the effects of Bidens pilosa ethylene acetate extract on L-NAME induced hypertension and oxidative stress in rats.

\section{Methods}

\section{Animals}

Male Wistar rats aged $10-12$ weeks and weighing 180 to $250 \mathrm{~g}$ were randomly selected from our colony. They were raised in the animal house of the Faculty of Sciences, University of Yaounde I, Cameroon in Plexiglas cages. All efforts were made to minimize animal suffering and to reduce the number of animals used. Rats were housed 3 per cages and exposed to daily $12 \mathrm{~h}$ light - dark cycle. They were maintained in a room temperature $\left(25 \pm 3{ }^{\circ} \mathrm{C}\right)$ with free access to a standard animal diet and tap water. All the procedures and protocols involving animals and their care were conducted in conformity with the institutional guidelines and approved by the Cameroon National Ethical Committee (Reg. No. FWA-IRB00001954). The effects of Bidens pilosa ethylene acetate extract (Bp) were examined in vivo at the end of the experimentation on mean arterial blood pressure (MABP) of rats previously treated with L-NAME (See Additional file 1).

\section{Plant material}

Fresh leaves of Bidens pilosa L (Asteraceae) were collected from Yaounde's suburb (Eleveur) on September 2011 and authenticated at the National Herbarium of Cameroon by comparison to the voucher specimen (No $65112 / \mathrm{HNC}$ ) deposited in 2005. The extraction was done as previously described [15]. Briefly, the ethyl acetate extract was prepared by macerating $1000 \mathrm{~g}$ of air dried leaves for two days in $5 \mathrm{~L}$ of methylene chloride/methanol (1:1). After filtration, the collected extract was concentrated using a rotary evaporator HEIDOLPH W2000, giving about $60 \mathrm{~g}$ of greenish dough. This extract was exhausted in $500 \mathrm{~mL}$ of ethyl acetate and after concentration using rotary evaporator, giving $12.7 \mathrm{~g}$ of ethyl acetate extract of $B$. pilosa. This extract was dissolved in 1\% DMSO for daily used (See Additional file 1).

\section{L-NAME -hypertension induction and treatment}

Wistar rats (30) were randomly divided into five groups of six rats. The first group (control) received a solution of DMSO (1\%), given according to the weight $(1 \mathrm{~mL} / 200 \mathrm{~g}$ of weight), while the second one (L-NAME group) received $\mathrm{L}$ - NAME (50 $\mathrm{mg} / \mathrm{kg} /$ day) plus the vehicle. The third group received at the same time L-NAME (50 $\mathrm{mg} / \mathrm{kg} /$ day) and losartan $(50 \mathrm{mg} / \mathrm{kg} /$ day), while the fourth and fifth groups received a combination of LNAME $(50 \mathrm{mg} / \mathrm{kg} /$ day) and Bidens pilosa ethylene acetate extract (Bp: 75 and $150 \mathrm{mg} / \mathrm{kg} /$ day respectively). All the treatments were administered daily orally for 4 weeks at the corresponding volume of $1 \mathrm{~mL} / 200 \mathrm{~g}$, from 8 to 8.30 AM using oesophageous cannula (See Additional file 1).

\section{Hemodynamic parameters recording}

At the end of the respective treatment, arterial blood pressure and heart rate of all rats were measured as previously described [17]. Briefly, the rat was anesthetized using an intraperitoneal injection of urethane $(1.5 \mathrm{~g} / \mathrm{kg})$. The trachea was exposed and cannulated to facilitate spontaneous breathing. The arterial blood pressure was measure from carotid artery via an arterial cannula connected to a pressure transducer coupled with a hemodynamic recorder Biopac Student Lab. (MP35) and computer (See Additional file 1).

\section{Blood and organs collection}

Immediately after hemodynamic parameters measurement, blood samples were collected from the abdominal artery, and centrifuged at $3000 \mathrm{rpm}$ for $15 \mathrm{~min}$. The plasma obtained was kept at $-20{ }^{\circ} \mathrm{C}$ for biochemical analysis. Thereafter, the heart, the kidney, the liver and the thoracic aorta were collected, washed in saline and weighed and kept for oxidative stress markers and $\mathrm{NO}$ evaluation.

\section{Biochemical analysis}

Heart, aorta, liver and kidney were dissected out and homogenized in Mc Even solution for heart and aorta or in Tris- $\mathrm{HCl} 50 \mathrm{mM}$ buffer solution for liver and kidney $(20 \%, w / v)$. Tissue levels of reduced glutathione (GSH), superoxide dismutase activity (SOD) and malondylaldehyde (MDA) were assayed using colorimetric method as described by Ellman, [18], Misra and Fridovich [19] and Wilbur et al. [20] respectively. The tissue concentration of nitric oxide (NO) was evaluated using the Griess 
method [21]. The concentrations of total cholesterol (TC), high density lipoprotein (HDL) cholesterol and triglycerides (TG), creatinin and bilirubine levels in serum were determined using commercial diagnostic kits (Fortress, UK). Atherogenic index was calculated following the formula used by Wakayashi and Kobaba [22]. The activities of alanine and aspartate aminotransaminases were also determined spectrophotometrically using commercial diagnostic kits (Fortress, UK).

\section{Statistical analysis}

Results were expressed as the mean \pm SEM. The difference between the groups was compared using one-way analysis of variance (ANOVA) followed by the Duncan's post hoc test. A value of $p<0.05$ was considered statistically significant.

\section{Results}

\section{Effects of ethylene acetate extract of Bidens pilosa on} arterial blood pressure and heart rate

Animals that received only L-NAME $(50 \mathrm{mg} / \mathrm{kg} /$ day) were hypertensive after four weeks of treatment. Concomitant administration of L-NAME with losartan (Los + L-NAME) or Bidens pilosa (Bp $75+$ L-NAME and Bp $150+$ L-NAME) dose-dependently and significantly prevented the installation of hypertension as depicted in Table 1. The mean arterial blood pressure (MABP) value was $166.18 \pm 2.68 \mathrm{mmHg}$ in L-NAME treated rats versus $128.43 \pm 1.45 \mathrm{mmHg}, 126.69 \pm 8.12$ and $110.03 \pm 8.19 \mathrm{mmHg}$ in the Los + L-NAME, Bp $75+$ L-NAME and Bp $150+$ L-NAME groups respectively. However, no significant change in heart rate was observed between experimental groups (Table 1).

\section{Effects of ethylene acetate extract of Bidens pilosa on lipid profile}

The oral administration of L-NAME $(50 \mathrm{mg} / \mathrm{kg})$ to rats resulted in an elevated plasma lipid profile (Table 2). L-NAME treated rats showed significantly $(p<0.01)$ higher levels of plasma triglycerides, LDL-cholesterol atherogenic index and significantly $(p<0.05)$ lower levels of HDL- cholesterol as compared to the normal control rats. The Bidens pilosa ethylene acetate extract
(Bp 75 and $150 \mathrm{mg} / \mathrm{kg} /$ day) significantly modulated the lipid profile in animals receiving concomitantly L-NAME. Bp extract reduced plasma triglycerides and LDL- cholesterol by $51.29 \%, 78.57 \%$ and $46.42 \%, 48.21 \%$ respectively as compared to L-NAME hypertensive rats. Bp also prevented the raise in atherogenic index. The extract increased the level of plasma HDL-cholesterol by $25.75 \%$ and $9.09 \%$ with the doses 75 and $150 \mathrm{mg} / \mathrm{kg}$ respectively as compared to L-NAME hypertensive rats. In the same conditions, losartan prevented the decrease of HDL-cholesterol by $18.18 \%(p<0.05)$, and the increase of LDL-cholesterol by $28.77 \%(\mathrm{p}<0.05)$ and triglycerides by $58.44 \%(p<0.01)$ as compared to L-NAME hypertensive rats.

\section{Effects of ethylene acetate extract of Bidens pilosa on liver and kidney functions}

As shown in Table 3 The oral administration of LNAME $(50 \mathrm{mg} / \mathrm{kg})$ to rats resulted in an increase of plasma AST and ALT by $106.92 \%$ and $58.34 \%$ ( $<<0.01$ ) respectively. In L-NAME hypertensive rats it is also observed an increase, but not significant in creatinin (10\%) and bilirubine $(35.32 \%)$ as well as a slight drop in proteins $(13.53 \%)$ as compared to nornotensive rats group. The combine administration of L-NAME and Bp $(75 \mathrm{mg} / \mathrm{kg}$ et $150 \mathrm{mg} / \mathrm{kg}$ ) prevented that increase for AST by $82.69 \%$ and $30.27 \%$ and for ALT by $70.14 \%$ and $80.38 \%$ respectively as compared to L-NAME hypertensive rats. Losartan induced a significant decrease of the plasma level of AST by $80.75 \%$ and of AST by $38.79 \%$ as compared to L-NAME hypertensive group. Bp extract prevented the increase induced by L-NAME of plasma creatinin by $35.22 \%$ at the dose of $75 \mathrm{mg} / \mathrm{kg}$ and by $28.40 \%$ at the dose of $150 \mathrm{mg} / \mathrm{kg}$ as compared to hypertensive group.

\section{Effects of ethylene acetate extract of Bidens pilosa on oxidative stress parameters}

The level of malondialdehyde (MDA) significantly $(p<0.01)$ increased in aorta, heart, liver and kidneys of rats which received L-NAME compared to control normotensive group. Apart from aorta and liver with $\mathrm{Bp}$ $(75 \mathrm{mg} / \mathrm{kg}$ ), the combined treatment with $\mathrm{Bp}$ (75 and

Table 1 Effects of ethylene acetate extract of Bidens pilosa on blood pressure and heart rate

\begin{tabular}{llllll}
\hline Parameters & \multicolumn{5}{l}{ Treatments } \\
\cline { 2 - 6 } & Vehicle $(10 \mathrm{ml} / \mathrm{kg})$ & L-NAME & L-NAME + Bp $(75 \mathrm{mg} / \mathrm{kg})$ & L-NAME + Bp $(150 \mathrm{mg} / \mathrm{kg})$ & L-NAME + Losartan \\
\hline DBP $(\mathrm{mm} \mathrm{Hg})$ & $104.14 \pm 7.42$ & $158.96 \pm 2.29^{\mathrm{b}}$ & $122.22 \pm 8.04^{\beta}$ & $105.28 \pm 8.22^{\beta}$ & $123.79 \pm 1.32^{\beta}$ \\
SBP $(\mathrm{mm} \mathrm{Hg})$ & $117.56 \pm 8.66$ & $180.62 \pm 4.08^{\mathrm{b}}$ & $135.64 \pm 8.56^{\beta}$ & $119.52 \pm 8.20^{\beta}$ & $137.72 \pm 3.20^{\beta}$ \\
MABP $(\mathrm{mmHg})$ & $108.61 \pm 7.75$ & $166.18 \pm 2.68^{\mathrm{b}}$ & $126.69 \pm 8.12^{\beta}$ & $110.03 \pm 8.19^{\beta}$ & $128.43 \pm 1.45^{\beta}$ \\
HR (beat $/ \mathrm{min})$ & $334.21 \pm 10.51$ & $311.48 \pm 14.14$ & $314.02 \pm 13.14$ & $352.20 \pm 15.74$ & $345.30 \pm 12.82$ \\
\hline
\end{tabular}

Each value represents a means \pm S.E.M. of 6 rats; ${ }^{\mathrm{b}} P<0.01$, significantly different compared to normal rats. ${ }^{\beta} P<0.01$, significantly different compared to L-NAME hypertensive rats

$D B P$ diastolic blood pressure, SBP systolic blood pressure, MABP mean arterial blood pressure, HRheart rate 
Table 2 Effects of ethylene acetate extract of Bidens pilosa on lipid profile

\begin{tabular}{|c|c|c|c|c|c|}
\hline \multirow[t]{2}{*}{ Parameters } & \multicolumn{5}{|l|}{ Treatments } \\
\hline & Vehicle $(10$ ml/kg) & L-NAME & L-NAME + Bp (75 mg/kg) & L-NAME +Bp (150 mg/kg) & L-NAME + Los (25 mg/kg) \\
\hline Total Chol (mmol/L) & $1.14 \pm 0.10$ & $1.22 \pm 0.07$ & $1.13 \pm 0.12$ & $1.00 \pm 0.14$ & $1.18 \pm 0.05$ \\
\hline HDL chol (mmol/L) & $0.91 \pm 0.13$ & $0.66 \pm 0.10^{a}$ & $0.83 \pm 0.11^{a}$ & $0.72 \pm 0.16$ & $0.78 \pm 0.09$ \\
\hline LDL chol (mmol/L) & $0.24 \pm 0.06$ & $0.56 \pm 0.08^{\mathrm{a}}$ & $0.30 \pm 0.04$ & $0.29 \pm 0.03^{\beta}$ & $0.40 \pm 0.12$ \\
\hline Triglycerides (mmol/L) & $0.61 \pm 0.06$ & $1.54 \pm 0.05^{b}$ & $0.75 \pm 0.27^{a}$ & $0.33 \pm 0.11^{\beta}$ & $0.64 \pm 0.22^{\beta}$ \\
\hline Atherogenic index (mmol/L) & $0.34 \pm 0.01$ & $0.67 \pm 0.07^{\mathrm{a}}$ & $0.39 \pm 0.08^{a}$ & $0.28 \pm 0.05^{\beta}$ & $0.51 \pm 0.07$ \\
\hline
\end{tabular}

Each value represents a means \pm S.E.M. of 6 rats; ${ }^{a} P<0.05{ }^{b} P<0.01$, significantly different compared to normal rats. ${ }^{a} P<0.05,{ }^{\beta} P<0.01$, significantly different compared to L-NAME hypertensive rats

$150 \mathrm{mg} / \mathrm{kg} /$ day) for 4 weeks significantly prevented the rise in tissue MDA levels in the rest of investigated organs as compared to L-NAME hypertensive rats. The same effect was observed with losartan $(25 \mathrm{mg} / \mathrm{kg} /$ day $)$.

Treatment of rats with L-NAME dropped significantly the glutathione (GSH) level in aorta, kidneys, liver, $(p<0.001)$ and heart $(p<0.05)$ when compared with control group. So, the decline percentages were 76.92 , $34.13,57.65$ and $54.873 \%$ respectively in aorta, heart liver and kidney. The L-NAME treatment associated with Bp extract or losartan has significantly prevented that decrease in all the investigated organs, except with the lower dose of $\mathrm{Bp}(75 \mathrm{mg} / \mathrm{kg})$ in the heart, the liver and the kidney. The same Effect has been observed with losartan in the kidney when compared with L-NAME hypertensive rats.

The administration of L-NAME in rats significantly decreased activity of SOD in aorta, heart, liver $(p<0.01)$ and kidneys ( $\mathrm{p}<0.05$ ), when compared to control group. The values of decline percentages were 38.80, 52.08, 54.36 and $33.54 \%$ in aorta, heart liver and kidney respectively as compare to control normotensive rats group. Bp extract at the doses of 75 and $150 \mathrm{mg} / \mathrm{kg}$ blunted significantly the decrease in SOD activity in heart and liver $(\mathrm{p}<0.01)$ observed in hypertensive group. Losartan also blunted significantly $(\mathrm{p}<0.01)$ the decrease of SOD in heart and liver.

Aortic, cardiac, liver and kidney content in NO are represented in Fig. 1d. In rats treated only with L-NAME, all the NO concentration decrease significantly $(\mathrm{p}<0.01)$ by
$38.16,38.84,62.28$ and $34.16 \%$ in aorta heart liver and kidney respectively as compared to the control normotensive rats. The $\mathrm{Bp}$ extract dose-dependently prevented the deleterious effects of L-NAME in the tissue $\mathrm{NO}$ content. It prevented by $33.33,10.86,16.07$ and $22.15 \%$ at the dose $75 \mathrm{mg} / \mathrm{kg} /$ day and by $148.71,12.5$, 42.85 and $36.70 \%$ at the dose $150 \mathrm{mg} / \mathrm{kg} /$ day the concentration of $\mathrm{NO}$ in the aortic, cardiac liver and kidney tissues respectively as compared to the L-NAME hypertensive group. Losartan had a similar effect.

\section{Discussion}

This study investigated the antihypertensive effect of Bidens pilosa ethylene acetate (Bp) extract in L-NAMEinduced hypertensive rats and its effects on oxidative stress as well as its damages on liver and kidney. The sustained L-NAME induced hypertension was confirmed [23]. The fact that Bp could prevent hypertension induced by L-NAME indicates that it may act directly or no in NO production or activity. As already mentioned, Bidens pilosa extract used in the present study contains many flavonoids namely Quercetin 3,3 '-dimethyl ether 7-0- $\beta$-D-glucopyranoside and Iso-Okanin 7-O- $\beta$-D-(2 “, 4", 6 "-triacetyl)-glucopyranoside. Previous studies have demonstrated that quercitine was able to improve endothelium function by increasing the bioavaibility and/or the production of NO [16]. In addition quecitine isolated from Bidens pilosa can prevent and attenuate hypertension [24]. This ability passes trough its vasodilatator, cardio protective and vasoprotective effects as well as its

Table 3 Effects of BPEA on liver and kidney functions

\begin{tabular}{|c|c|c|c|c|c|}
\hline \multirow[t]{2}{*}{ Parameters } & \multicolumn{5}{|l|}{ Treatments } \\
\hline & Vehicle $(10 \mathrm{ml} / \mathrm{kg})$ & L-NAME (50 mg/kg) & L-NAME + Bp (75 mg/kg) & L-NAME + Bp (150 mg/kg) & L-NAME + Los $(25 \mathrm{mg} / \mathrm{kg})$ \\
\hline$\overline{\mathrm{AST}}(\mathrm{UI})$ & $31.03 \pm 2.08$ & $64.21 \pm 6.73^{b}$ & $11.11 \pm 0.87^{\mathrm{b} \beta}$ & $45.68 \pm 5.16^{\mathrm{a} \beta}$ & $12.36 \pm 1.07^{\mathrm{a} \beta}$ \\
\hline $\operatorname{ALT}(U \mathrm{I})$ & $18.51 \pm 1.78$ & $29.31 \pm 2.30^{b}$ & $11.75 \pm 1.15^{\mathrm{b} \beta}$ & $10.72 \pm 0.21^{\mathrm{b} \beta}$ & $17.94 \pm 2.86^{\beta}$ \\
\hline Creatinin (mg/mL) & $0.80 \pm 0.06$ & $0.88 \pm 0.68$ & $0.57 \pm 0.06$ & $0.63 \pm 0.18$ & $0.87 \pm 0.45$ \\
\hline Bilirubine (mg/L) & $4.02 \pm 1.38$ & $5.44 \pm 1.707$ & $5.63 \pm 0.92$ & $5.71 \pm 1.058$ & $8.04 \pm 1.79^{a}$ \\
\hline Proteins (mg/mL) & $81.84 \pm 2.57$ & $70.76 \pm 14.69$ & $75.04 \pm 14.10$ & $85.20 \pm 12.79$ & $71.32 \pm 15.94$ \\
\hline
\end{tabular}

Each value represents a means \pm S.E.M. of 6 rats; ${ }^{\text {a }}<0.05^{\mathrm{b}} \mathrm{P}<0.01$, significantly different compared to normal rats. ${ }^{a} \mathrm{P}<0.05$, ${ }^{\beta} \mathrm{P}<0.01$, significantly different compared to L-NAME hypertensive rats 


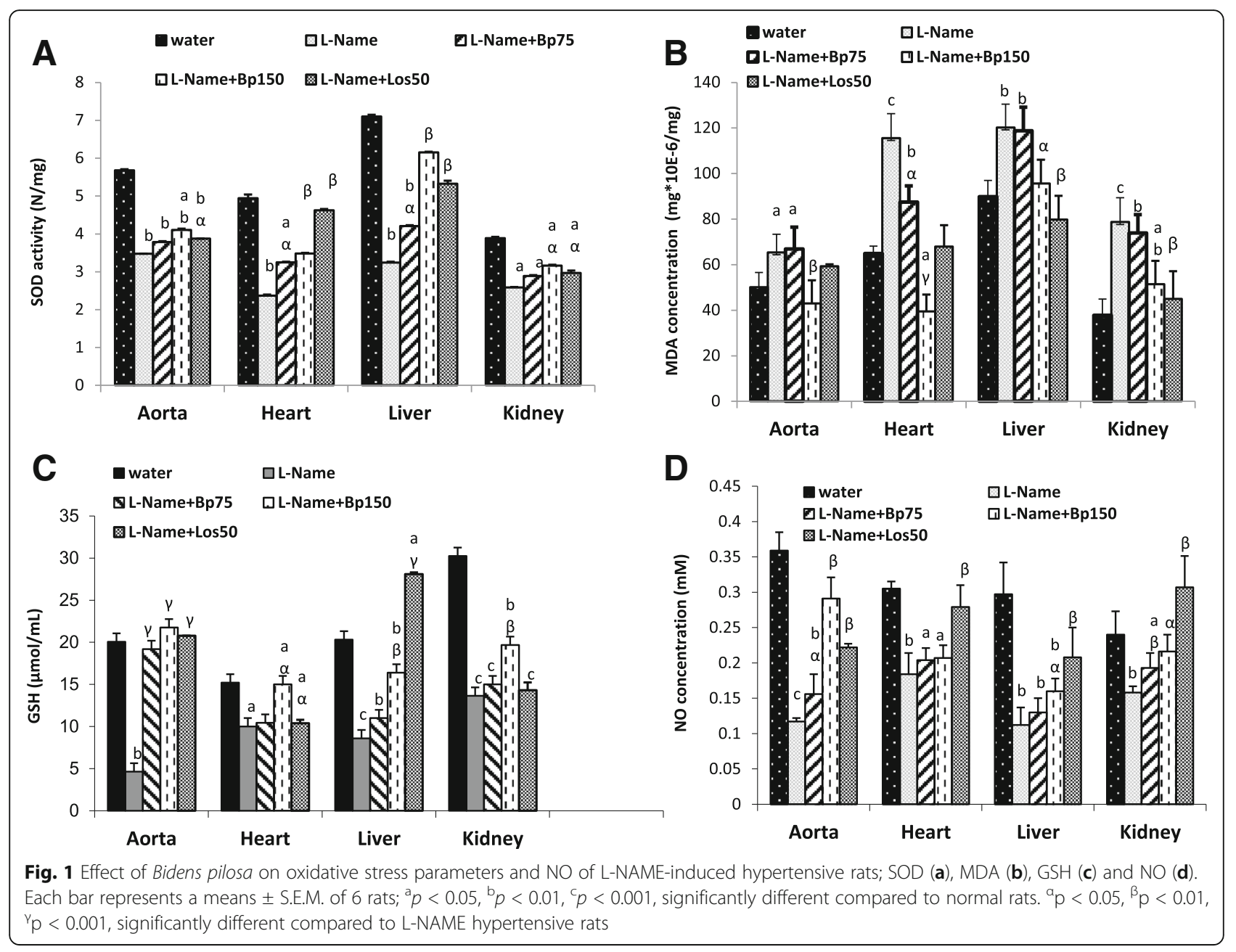

antioxidant properties $[10,11,13]$. Quecitine can also prevent cell smooth muscle proliferation and migration [25]. We can also think of the calcium blocker activity of the plant that has been demonstrated [26]. All this might have contributed at least in part in the process of the plant extract to prevent the induction of hypertension by L-NAME administration. The fact that none of the treatment has affected the heart rate is in accordance with previous studies that have shown that, the chronic administration of L -NAME did not alter the heart rate [27]. Since no changes in the heart rate were also found in rats treated concomitantly with L-NAME and Bp extract, it seems that the lowering of blood pressure may be predominantly due to its effects on vessels. Though Dimo et al. [13] have demonstrated that Bidens pilosa reduced heart rate and the force of contraction; other studies using other extracts of Bidens pilosa showed that the plant does not really affect the heart, but mostly the vessels [8]. This difference may be due to the difference in extraction. Therefore, we can suggest that the antihypertensive effect of our plant extract might be mainly due to its ability to reduce the peripheral resistance via its vasodilating activities [8].

The fact that the dyslipidemia observed in L-NAMEinduced hypertensive rats, was significantly managed by both losartan and BPEA confirmed both the hypotriglyceridemic and hypocholesterolemic properties of the plant extract $[9,10,12]$. In fact, L-NAME elevates the serum concentrations of free fatty acid by lowering the activity of hepatic carnitine palmitoyltransferase, the rate-limiting enzyme of fatty acid oxidation, leading to hyperlipidemia [28]. The elevation in serum triglyceride and cholesterol might be due to reduced fatty acid oxidation [28]. The hypolidemic potential of Bidens pilosa may therefore be due, at least in part, to the stimulation of fatty acid oxidation, related to the presence of quercetin which may be involved in lipid metabolism [29]. Quercitine is also known to reduce triglyceride circulation level [30]. This in turn might contribute to the cardiovascular protective effects of Bp. The antilipidemic properties of Bp extract could also be due to its antioxidant composition [7]. In effect, in our study, the 
oxidative status was impaired in L-NAME treated group. The association of Bp or losartan with L-NAME prevented the decrease of glutathione and SOD and the increase of MDA in treated rats. Glutathione plays an excellent role in protecting cell from oxidative damages. Therefore Bp may be acting as membranes protector to prevent the lipid peroxidation or as free radicals scavenger [16]. That action of our plant extract may in turn protect the organs against the injuries caused by free radicals. The antioxidant potential of Bp might also be due to the free radical scavenging properties of its known phytochemicals such as flavonoids, phenylpropanoids and phenols $[6,7]$. This can then explain the protective effect of our extract on liver and kidney. In the present study, we evaluated the toxicity L-NAME-induced hypertension on these two organs by assessing the level of blood creatinine, bilirubine and transaminases (AST and ALT). Bidens pilosa inhibited the elevation in serum levels of AST, ALT and bilirubine induced by L-NAME; that is similar with the effect on oxidative stress markers. This may indicate that oxidative stress contributes in the mechanism(s) of hepatotoxicity due to chronic consumption of L-NAME. The low level of serum enzyme activity following the concomitant treatment with $\mathrm{Bp}$ as compared to untreated rats confirms the liver and kidney protective effects of Bidens pilosa [6] as well as its antioxidant activity [7]. In the present study, treatment with L-NAME increased the blood pressure in association with decreased in heart and aortic NO tissue levels. The levels of heart and aortic NO were reversed by co-administration of $\mathrm{Bp}$ showing the protective effect of the plant extract on the vascular endothelium. This beneficial effect of the plant extract may be associated with the presence of substances which are reported to improve vascular function by endotheliumdependent and independent manner and increase NO bioavailability and/or production $[16,31]$.

\section{Conclusion}

These results showed that the ethylene acetate extract of Bidens pilosa leaves might prevent the L-NAME-induced hypertension in rats. Current findings also confirm that Bidens pilosa is able to normalize lipid profile, fight against oxidative stress and cell damage in liver and kidney and to improve endothelial function in this animal model of hypertension. These results are probably due to the presence of Quercetin 3,3'-dimethyl ether 7-0- $\beta$-Dglucopyranoside and scientifically confirm the antihypertensive and antioxidative properties of the aqueous extract of B. pilosa as used in Cameroonian traditional medicine.

\section{Additional file}

Additional file 1: Animal handling procedure. (DOCX $615 \mathrm{~kb}$ )

\section{Abbreviations}

ALT: Alanine amino-transferase; AST: Aspartate amino-transferase; Bp: Bidens pilosa ethylene acetate extract; DBP: Diastolic blood pressure; GSH: Reduced glutathione; HDL-c: High density lipoprotein cholesterol; HR: Heart rate; LDL-C: Low density lipoproteins cholesterol; L-NAME: Nw-nitro-L-arginine methyl ester; MABP: Mean arterial blood pressure; MDA: Malondialdehyde; NO: Nitric oxide; SBP: Systolic blood pressure; SOD: Superoxide dismutase activity

\section{Acknowledgements}

Not applicable.

Funding

Not applicable.

\section{Availability of data and materials}

All data are contained and described within the manuscript. The datasets used and/or analyzed during the current study available from the corresponding author on reasonable request.

\section{Authors' contributions}

DCB, LK and PDDD carried out the study; CDB and PDDD wrote the manuscript. BFOA and LT helped to analyze data, PK and TD supervised the work. All authors read and approved the final manuscript.

\section{Ethics approval}

All the procedures and protocols involving animals and their care were conducted in conformity with the institutional guidelines approved by the Cameroon National Ethical Committee (Reg. No. FWA-IRB00001954). All efforts were made to minimize animal suffering and to reduce the number of animals used.

\section{Consent for publication}

All authors gave their consents for the publication of the manuscript, and for Bilanda Danielle Claude to be the corresponding author.

\section{Competing interests}

The authors declare that they have no competing interests.

\section{Publisher's Note}

Springer Nature remains neutral with regard to jurisdictional claims in published maps and institutional affiliations.

\section{Author details}

'Department of Animal Biology and Physiology, Laboratory of Animal Physiology, University of Yaounde I, P.O. Box 812, Yaounde, Cameroon. ${ }^{2}$ Faculty of Health Sciences, Université des Montagnes, P.O. Box 208, Bangangté, Cameroon.

Received: 22 January 2017 Accepted: 12 September 2017

Published online: 10 October 2017

\section{References}

1. Moncada S, Higgs A. The L-arginine-nitric oxide pathway. N Engl J Med. 1993:329(27):2002-12.

2. Huang PL, Huang Z, Mashimo H, Bloch KD, Moskowitz MA, Bevan JA, Fishman MC. Hypertension in mice lacking the gene for endothelial nitric oxide synthase. Nature. 1995;377:239-42.

3. Rees DD, Palmer RMJ, Schulz R, Hodson HF, Moncada S. Characterization of three inhibitors of endothelial nitric oxide synthase in vitro and in vivo. $\mathrm{Br} J$ Pharmacol. 1990;101:746-52.

4. Rajendran P, Boobalan R. The flavonoid troxerutin ameliorates hypertension, oxidative stress and lipid metabolism in L-NAME hypertensive rats. Indo-Asian J Multidisciplin Res. 2015;1(3):280-9.

5. El-Sherbiny GA, Taye A, Abdel-Raheem IT. Role of ursodeoxycholic acid in prevention of hepatotoxicity caused by amoxicillin-clavulanic acid in rats. An Hepatol. 2009;8:134-40.

6. Kviecinski MR, Felipe KB, Correia JFG, Ferreira EA, Rossi MH, Gatti FM, Filho DW, Pedrosa RC. Brazilian Bidens pilosa Linne' yields fraction containing quercetinderived flavonoid with free radical scavenger activity and hepatoprotective effects Libyan. J Med. 2011;6:5651-62. 
7. Bartolome AP, Villaseñor IM, Yang WC. Bidens pilosa L. (Asteraceae): botanical properties, traditional uses, Phytochemistry, and pharmacology. Evid Based Complement Alternat Med. 2013;2013:1-51

8. Dimo T, Nguelefack TB, Kamtchouing P, Dongo E, Rakotonirina A Rakotonirina SV. Hypotensive effects of a methanol extract of Bidens pilosa Linn on hypertensive rats. C R Acad Sci III. 1999:322(4):323-9.

9. Dimo T, Azay J, Tan PV, Pellecuer J, Cros G, Bopelet M, Serrano JJ. Effects of the aqueous and methylene chloride extracts of Bidens pilosa leaf on fructose-hypertensive rats. J Ethnopharmacol. 2001;76(3):215-21.

10. Dimo T, Rakotonirina SV, Tan PV, Azay J, Dongo E, Cros G. Leaf methanol extract of Bidens pilosa prevents and attenuates the hypertension induced by high-fructose diet in Wistar rats. J Ethnopharmacol. 2002;83(3):183-91.

11. Hsin-Ling Y, Ssu-Ching C, Nai-Wen C, Jia-Ming C, Mei-Ling L, Pei-Chuan T, Han-Hsuan F, Wei-Wan K, Hsiao-Chi C, Hsuan-Hui W, You-Cheng $\mathrm{H}$. Protection from oxidative damage using Bidens pilosa extracts in normal human erythrocytes. F Chem Toxicol. 2006;44:1513-21.

12. Yu-Chuan L, Meng-Ting Y, Chuan-Ju L, Cicero LTC, Wen-Chin Y. Bidens pilosa and its active compound inhibit adipogenesis and lipid accumulation via downmodulation of the C/EBP and PPARy pathways. Sci Rep. 2016; doi:10.1038/24285.

13. Dimo T, Nguelefack TB, Tan PV, Yewah MP, Dongo E, Rakotonirina SV, Kamanyi A, Bopelet M. Possible mechanisms of action of the neutral extract from Bidens pilosa L. leaves on the cardiovascular system of anaesthetized rats. Res. 2003;17:1135-9.

14. Thiyagarajan R, Boobalan R. Antihypertensive, antihyperlipidemic and antioxidant influence of D-carvone in L-NAME induced hypertensive rats. Intern J Pharm Biol Arch. 2014;5(4):82-8.

15. Fotso AF, Longo F, Dzeufiet DPD, Kouam SF, Spiteller M, Dongmo AB, Savineau JP. Analgesic and antiinflammatory activities of the ethyl acetate fraction of Bidens pilosa (Asteraceae). Inflammopharmacol. 2014;22:105-14.

16. Abigail J, Larson J, David S, Thunder J. Therapeutic potential of quercetin to decrease blood pressure: review of efficacy and mechanisms. Adv Nutr. 2012;3:39-46.

17. Bilanda DC, Dimo T, Dzeufiet DPD, Bella NMT, Aboubakar OBF, Nguelefack BT, Tan VP, Kamtchouing P. Antihypertensive and antioxidant effects of Allanblackia floribunda Oliv. (Clusiaceae) aqueous in alcohol-and sucroseinduced hypertensive rats. J Ethnopharmacol. 2010;128:634-40.

18. Ellman GL. Tissue sulfhydryl groups. Arch Biochem Biophys. 1959;82:70-7.

19. Misra F. Determination of the level of superoxide dismutase in whole blood. Yale University Press, New Haven. 1972:101-9.

20. Wilbur KM, Bernheim F, Shapiro OW. Determination of lipid peroxidation. Arch Biochem Biophys. 1949;24:305-10

21. Bryan NS, Grisham MB. Methods to detect nitric oxide and its metabolites in biological samples. Free Radic Biol Med. 2007:43:645-57.

22. Wakayashi I, Kobaba WR. Effet de l'âge sur le rapport entre le boire et les rapports artherosclerotiques. Girontol. 2002;48:151-6.

23. Baylis C, Mitruka B, Deng A. Chronic blockade of nitric oxide synthesis in the rat produces systemic hypertension and glomerular damage. J Clin Invest. 1992;90:278-81.

24. Lei Y, Zhang JD, Wang B, Yi JLV, Hong J, Gui LL, Yun Q, Ming R, Xue FG. Quercetin inhibits left ventricular hypertrophy in spontaneously hypertensive rats and inhibits angiotensin II-induced H9C2 cells hypertrophy by enhancing PPAR-c expression and suppressing AP-1 activity. PLoS One. 2013;8(9):1-14.

25. Morales-Cano D, Menendez C, Moreno E, Moral-Sanz J, Barreira B, Galindo P, Pandolfi R, Jimenez R, Moreno L, Cogolludo A, Duarte J, Perez-Vizcaino F. The flavonoid quercetin reverses pulmonary hypertension in rats. PLoS One. 2014;9(12):1-20

26. Kouakou LK, Bléyéré MN, Amonkan AK, Konan AB, Kouakou AJC, Yapo PA, Ehilé EE. Calcium antagonist effects of a chromatographic fraction from bidens pilosa L. (Asteraceae) leaf aqueous extract on isolated rat heart. Intern J Biopharma. 2013;4(2):115-22.

27. Fortepiani LA, Ortiz MC, Atucha NM, Garcia-Estan J. Nebivol ameliorates nitric oxide deficient hypertension. The Sci W J. 2002;2:1676-84.

28. Khedara A, Kawai Y, Kayashita J, Kato N. Feeding rats the nitric oxide synthase inhibitor, I-N $\omega$ nitroarginine, elevates serum triglyceride and cholesterol and lowers hepatic fatty acid oxidation. J Nutr. 1996;126:2563-7.

29. Brüll V, Burak C, Stoffel-Wagner B, Wolffram S, Nickenig G, Müller C, Langguth P, Alteheld B, Fimmers R, Naaf S, Zimmermann BF, Stehle P, Egert S. Effects of a quercetin-rich onion skin extract on $24 \mathrm{~h}$ ambulatory blood pressure and endothelial function in overweight-to-obese patients with (pre-) hypertension: a randomised double-blinded placebo-controlled cross-over trial. British J Nutr. 2015:114:1263-77.

30. Hoek-van den Hil EF, Keijer J, Bunschoten A, Vervoort JJM, Stankova B, Bekkenkamp M, Herreman L, Venema D, Hollman PCH, Tvrzicka E, Rietjens IMCM, Schothorst EM. Quercetin induces hepatic lipid omega-oxidation and lowers serum lipid levels in mice. PLoS One. 2013;8(1):1-10.

31. Khoo NKH, White CR, Miller LP, Zhou F, Constance C, Inoue T, Patel RP, Dale PA. Dietary flavonoid quercetin stimulates vasorelaxation in aortic vessels. Free Radic Biol Med. 2010;49(3):339-47.

\section{Submit your next manuscript to BioMed Central and we will help you at every step:}

- We accept pre-submission inquiries

- Our selector tool helps you to find the most relevant journal

- We provide round the clock customer support

- Convenient online submission

- Thorough peer review

- Inclusion in PubMed and all major indexing services

- Maximum visibility for your research

Submit your manuscript at www.biomedcentral.com/submit
Biomed Central 